\title{
Experiences of First Nations adolescents living with type 2 diabetes: a focus group study
}

\author{
Brandy Wicklow MD MSc, Allison Dart MD MSc, Jackie McKee, Arlene Griffiths RN BScN, Sayma Malik PsyD, \\ Shayna Quoquat, Sharon Bruce PhD
}

Cite as: CMAJ 2021 March 22;193:E403-9. doi: 10.1503/cmaj.201685

\begin{abstract}
BACKGROUND: Despite prevention efforts, type 2 diabetes mellitus continues to increase in incidence among First Nations children and is associated with early and aggressive complications. We aimed to determine the experiences of adolescents living with type 2 diabetes and the barriers to living well with type 2 diabetes that adolescents perceived.
\end{abstract}

METHODS: We recruited adolescents with type 2 diabetes mellitus from the pediatric diabetes clinic in Winnipeg, Manitoba, to participate in a day-long facilitated focus group discussion. Group discussions were recorded and transcribed verbatim. We used interpretive description methodology to inform the thematic analysis of the transcripts.

RESULTS: Eight adolescents with a mean age of 15 years participated. Five adolescents identified as female; most were Indigenous (7/8). The mean duration since diagnosis of diabetes was 2.5 years. Adolescents reported struggling with acceptance of their diagnosis, with the stigma and shame associated with the diagnosis and with daily self- management tasks. Three themes were developed from the focus group discussions: bearing witness, the "weight" of diabetes and support (lack of support).

INTERPRETATION: Adolescents with diagnoses of type 2 diabetes experience associated stigma and shame, which are substantial barriers to selfcare. A broader understanding of their lived experience, including the socioecological and emotional context, could help to improve health care provision and intervention strategies for this population.
A dolescent-onset type 2 diabetes mellitus, first described in the 1990s, has continued to increase in incidence worldwide, despite substantial efforts at prevention..$^{1,2}$ In Canada, First Nations children are disproportionally affected ${ }^{3}$ as a result of colonial processes which manifest in increased disease risks; these processes and risks include dispossession from land, decreased access to educational and employment opportunities, substandard and crowded housing and food insecurity. In addition, access to appropriate and culturally safe health care is limited for many First Nations people. From the perspective of care providers, management of adolescent type 2 diabetes is difficult because of limited pediatric patient responses to lifestyle interventions and pharmacotherapy designed for adults. ${ }^{4,5}$ From the perspective of adolescents, management of chronic illness occurs within a broad environment of family, friends and community. An understanding of the individual experiences of adolescents with diabetes within this broader context is needed to inform relevant culturally safe and effective holistic health care.

It is important to include people in health research who have lived experience with the condition of interest to ensure that patient priorities are considered, ultimately leading to improved outcomes..$^{6-8}$ Patients prefer practical clinical trials that measure the effect of treatments on health outcomes identified and prioritized by patients. ${ }^{7}$ Patient engagement in the research process has been shown to improve patient enrolment, retention and reporting and dissemination of study findings. ${ }^{6}$ In our clinical and research practice, many of the adolescents with whom we work are First Nations. The history of research with First Nations people includes exploitive relationships and lack of benefit for First Nations people and communities. Researchers have received guidance on conducting ethical research with First Nations people and communities, which includes, but is not limited to, establishing and maintaining meaningful relationships, reorienting power structures and including Indigenous knowledge. ${ }^{9-11}$

To advance patient-oriented research into the wellness of adolescents and their families living with type 2 diabetes, we conducted a focus group of adolescents with type 2 diabetes to document their lived experiences with the diagnosis, health care services, self-management and self-identified barriers to living well with type 2 diabetes. 


\section{Methods}

We designed a qualitative study in which adolescents living with type 2 diabetes participated in a 1-day, facilitated focus group discussion on the experience of living with type 2 diabetes. We report our findings according to the standards of the Consolidated Criteria for Reporting Qualitative Research (COREQ). ${ }^{12}$

\section{Research team}

The research team included clinician researchers with expertise in pediatric endocrinology (B.W.), pediatric nephrology (A.D.), child health psychology (S.M.), community-based nursing (A.G.) and qualitative study expertise (S.M. and S.B.). J.M. and S.Q. are self-identified Indigenous women who live with type 2 diabetes. J.M. is also the mother of an adolescent with type 2 diabetes. Both women participated in the focus groups and helped with data analysis, including interpretation and manuscript writing. S.M. and A.G., who facilitated the focus groups, both identify as female settlers.

\section{Participant recruitment}

We recruited adolescents with type 2 diabetes through the outpatient pediatric type 2 diabetes clinics at the Diabetes Education Resource for Children and Adolescents in Winnipeg, Manitoba. We included adolescents who were diagnosed with type 2 diabetes, spoke English, lived within driving distance from Winnipeg and were willing to share their lived experience. Clinicians approached adolescents and their caregivers during a routine clinic visit to ask about interest in participation.

\section{Focus group procedures}

We developed a framework to facilitate group interactions with the following objectives: to establish a supportive group and a safe space, where adolescents felt free to share feelings and experiences without judgment, to practise cultural humility as a research team and to learn from group members about concerns and priorities for their health and management of type 2 diabetes, specifically as it relates to the period of adolescence. All adolescents and their caregivers provided informed consent to participation, recording, analysis and publication of the discussion.

As focus group facilitators, S.M. and A.G. introduced themselves to the group by describing their training, background and family lineage. The meeting began with an opening prayer given by an Elder, with an offering of tobacco as part of the Ceremonial Opening of the session. The Elder then participated with the caregiver focus group. We used warm-up activities to introduce the advisory group members to one another and set the tone for the day regarding safe and respectful sharing. We then divided the group participants into adolescent and caregiver groups; each group was facilitated separately (S.M. and A.G.), which offered a more intimate space for sharing among their respective cohorts. This paper reports on the adolescent focus group.

We posed the following open-ended questions to the group: What does living with type 2 diabetes mean to you? How has living with type 2 diabetes affected your life? What does type 2 diabetes mean to your family? How important is managing type 2 diabetes? What are your priorities for the management of type 2 diabetes? What supports are needed to successfully manage type 2 diabetes? What role does stress play in managing type 2 diabetes? How has living in a First Nations community affected your type 2 diabetes management? What are the biggest challenges facing adolescents with type 2 diabetes? What is the most pressing message you would like to share with our research team? Who else needs to hear this message? What do you think are the most useful ways to share this information?

Participants reviewed the list of questions and prioritized the questions that were most important to them. The adolescent group focused on "what type 2 diabetes means," "impact of type 2 diabetes," "importance of managing type 2 diabetes," and "supports." Participants were also encouraged to suggest alternate questions to explore within their respective groups; the adolescent group chose "life goals." Facilitators encouraged equal participation among the participants in each group.

\section{Data analysis}

Group discussion was recorded and transcribed verbatim by a court reporter. We analyzed the discussions using thematic analysis, informed by interpretive description. ${ }^{13}$ Interpretive description is an inductive qualitative research approach, with the goal of finding meaning in participants' explanations that may yield implications for practical (clinical) application. ${ }^{13,14}$ Epistemologically, interpretive description aligns with the qualitative paradigm that multiple realities are considered to exist, as opposed to singular truths, and knowledge production occurs via the relationship between researcher and participants. The approach seeks to find meaning beyond surface descriptions of the phenomenon under study to ensure that questions are relevant to the participants and their contexts, so that findings are applicable to their circumstances.

We completed repeated line-by-line readings of the transcripts to become immersed in and "know" the data. Using the research questions as a guide, the first stage of coding entailed developing multiple surface-level concepts representing the phenomenon under study. Examples of concepts include fear, anxiety and financial cost. The next stage entailed reviewing concepts, identifying connections and creating categories. Categories encapsulate the broader relationships between concepts. Finally, we identified an overarching category to represent a broader experience of the phenomena and encapsulate the more specific concepts. At each stage, we created memos regarding the rationale behind the coding and relationships to other categories. Research team members and focus group participants reviewed the thematic analysis of the focus groups to ensure accuracy and authenticity of the analysis.

\section{Governance}

The adolescents with type 2 diabetes are full partners on the research described in this paper. The lead author (B.W.) has assumed the role as steward of the data. Our study was done using a strengths-based approach, as opposed to a deficit approach. This meant that data collection, analysis and interpretation were 
done with the lens that our youth and their community members were resilient, and that barriers to care are not because of individual or family choices or deficits. The settler health care providers undertook this work from the position of learners and the perspective of cultural humility, acknowledging the role that power plays in the distribution of disease, risk factors and treatment. The philosophies of sovereignty and self-determination informed the development of the focus group and this research, in that the settler researchers were guided by the goals of the participants. The research received approval from our Indigenous stakeholder group, which includes Elders, Indigenous health care providers, community members and Indigenous research scholars. The results of this thematic analysis have been presented to the participants and the Indigenous stakeholder group to ensure authenticity of the interpretation.

\section{Ethics approval}

We obtained ethics approval for the study from the University of Manitoba Research Ethics Board (HS13255 B2011:024).

\section{Results}

Participating adolescents $(n=8)$ were primarily Indigenous $(7 / 8)$ and included mostly self-identifying females (5/8), with a mean age of 15 years and diabetes duration of 2.5 years. Three main themes, bearing witness, "weight" of diabetes and support (lack of support) emerged from the focus group discussions and encompassed several subthemes outlined below. We have included several quotes that came from discussions of each of the main themes.

\section{Bearing witness}

Adolescent study participants have observational knowledge of diabetes based on their family members who live with diabetes. In addition, adolescents have experiential knowledge of their family members' diabetes, in the sense that they not only observe the illness experiences of others, but they, as family members, live the family experience of diabetes. The impact of bearing witness to diabetes was evident in participant reflections on diagnosis and complications, as outlined in the subcategories below.

\section{Trauma of diagnosis}

All adolescent participants remembered the occasion of their diabetes diagnosis vividly. Adolescents recalled feeling fear, dread and confusion upon learning they had diabetes.

I remember that day ... I remember hearing. I could hear my [parent] crying and everybody panicking and the doctor trying to explain ... what it was ... my heart just sank because I was, no. It's like devastation. It's like I just felt devastated when I heard (Adolescent 1).

Well, at first I didn't know what it was...And then after, then after they started taking me to the ... diabetes clinic and showing me how to do a shot and I started to get scared and I started crying ... (Adolescent 6).

And you're like, oh, what am I going to do, how am I going to ... what am I going to do? (Adolescent 2).
And depression's a big part of having diabetes because once you find out you're diabetic, you go into this depression state (Adolescent 2).

Only 1 participant indicated that the diagnosis was not devastating. It didn't stop me (Adolescent 5).

\section{Fear of complications}

Adolescents expressed knowledge about and fear of diabetes complications, including infections, loss of limbs and kidney disease. Adolescent study participants had received their diagnosis 2.5 years previously, on average, yet showed advanced knowledge of diabetes complications and comorbidities.

I don't know like if you guys ever had this, like when you're ... you, like you think your sugars are high and you're like starting to panic (Adolescent 1 ).

Like my biggest fear is infection. Oh, I hate infections (Adolescent 2).

You know, [my family member] had 4 of their toes cut off and they had that other leg cut off too and then shortly after they died because they never took care of themselves (Adolescent 1 ).

I don't want to lose any limbs (Adolescent 4).

Yes. Well, like my, like my [family member] ... they were always a bad diabetic. They're on dialysis and they still drink. I'm like ... They're just a ticking time bomb. Like, honestly ... (Adolescent 3).

My [family member], they lost both their legs to diabetes and it's been really hard because they used to be a [outside worker] ... And, I don't know, all of a sudden like this time a couple years ago, they were driving around doing everything themselves. Now they can't. They're at home in a wheelchair, both their legs cut off, waiting for their fake ones (Adolescent 2).

... you have to be careful whatever you do. You have to be careful that you don't break any bones, that you don't cut your leg or ... cut your skin. Because then you have cracks in your skin and ... it splits, and it takes forever to heal (Adolescent 2).

Well, depends on how your sugar levels are, they say .... If your sugar levels are always high, it takes a longer time to heal (Adolescent 6).

\section{"Weight" of diabetes}

Adolescent participants described diabetes as a burden, and the day-to-day experience of living with diabetes as challenging, confusing and unfair. The weight or heaviness of diabetes was discussed in relation to the subcategories of causation and self-surveillance.

\section{Causation}

Adolescents struggled to understand why they had diabetes, and the causal explanations they advanced touched on multiple domains. Adolescents identified genetics as having a large causal role, but had difficulty reconciling the historical past with the present. 
I guess for me, you know, when we talk about genetics, I was reading somewhere for how long diabetes has existed. So back then, there was no such thing as diabetes. So how did genetics come into, you know .... So does that mean that, you know, we all carry it? This is confusing. Does that mean that our people have carried that gene? To me, I don't believe that they did (Adolescent 4).

Yes, it's kind of a confusing thing about genetics. Like before, we didn't have it, but I think everybody has a little bit of diabetes in them, but they just don't have as much ... But with the food and the junk food, that kind of gives it a boost ... to get started (Adolescent 2).

Although adolescents tried to reconcile a historical past without diabetes and the current high diabetes prevalence within their communities and families, they all agreed that genetics was somehow involved because diabetes clustered in families.

Yes, my [family member] was really active and they just recently got diagnosed with diabetes, but everyone's like how, you were so active? Even if you were active, they were part of the family and ... it's hereditary (Adolescent 3).

Genetics, that's how I'm diabetic (Adolescent 5).

The thing about the hereditary part of it, like my [family member 1] was always trying to scare me. They're like, you know, I don't think [family member 2] told you this, but like your [family member 3] had their leg amputated from diabetes. [Family member 1] was like trying to scare me into smartening up because they're like, if you don't stop the way you're behaving with your diabetes, you're going to lose both your legs. It kind of scared me. I was, I don't want to lose both my legs, no, I don't want, no. So, I kind of stopped what I was doing and started doing what I was supposed to. It started sort of scaring me a little bit (Adolescent 1).

Like my [parent] knows diabetes. It runs through in, throughout their family. Like their mom had it, their dad ... just about all [the brothers and sisters] have it (Adolescent 2).

Although they agreed that genetics was part of the causal chain for diabetes, they struggled to understand why they as individuals had diabetes.

Yes. So, genetics really kicked my ass. Like it skipped over my [family member] and went straight to me. I'm like why didn't they get it? Why don't they have it too? This is so unfair (Adolescent 2).

Even though adolescents expressed a strong belief in the role of genetics and heritability, they also appeared to blame themselves.

When I think of being like, getting diabetic, like I could really see it because how my lifestyle was. I was always eating junk food and from my [family member 1], because I'd always go to visit them and ... then I started gaining weight and then by 9 I got really sick and [family member 2] took me to the hospital and they said you have diabetes (Adolescent 4).

Yes, because whenever l'd drink tea as a kid, I would dump sugar ... . Because I love sweets ... (Adolescent 3).

Yes, because I know it's my fault and I should have listened (Unknown speaker).
Yes. Like self-blame is really, because when I was younger, I used to eat like crazy. I don't know because, I don't know, everybody else would eat lots, so I would eat lots too. And now that I'm getting older and that I have diabetes, I'm like I got to slow down. I started thinking like that when I was about 14 (Adolescent 2).

I think that what - throughout my life, I've been told to be careful with my sugars, even as a kid. Still didn't listen, and I find it stupid that I didn't listen (Adolescent 4).

I'm like it's not my fault. Yes, it's your fault because you're a lazy ass (Adolescent 1 ).

Adolescents said they felt others blamed them as well.

And I hate going to doctors because they know I'm diabetic, right, and they keep on blaming me like it's my fault, even though it kind of is, but it's totally, not totally my fault. They're like, oh, stop eating a bunch of junk food, stop eating so much. I'm like, I have, I'm not eating as much. I totally cut it in half. I barely eat junk food, once in a while. And I still have diabetes. They act like it's my fault (Adolescent 2).

[Regarding blame from clinicians] Be more understanding (Adolescent 4).

[Regarding blame from clinicians] Yes, because, well, just about all my family has it, so it's totally not all my fault. I guess kind of, not all of it (Adolescent 2).

The family of one adolescent participant did not support a model of individual responsibility.

Well I don't know. It's just been in the family for a long time, as they say. ... So I think my parents were like, it's not your fault, it's been in the family. Just be yourself and go, just don't let it stop you (Adolescent 5).

\section{Self-surveillance}

Adolescents described the day-to-day management of diabetes as difficult and all consuming.

Not easy, it sucks, in my opinion, sometimes (Adolescent 1 ).

It's a lot of responsibility.... It's like a job (Adolescent 4).

Adolescents found the self-monitoring of food, blood glucose and weight to be especially difficult in relation to the behaviours of their friends and other adolescents.

Like, and it's incredibly hard for young people to manage diabetes than an older person because we're around it [snack and junk food] more. Like all our friends that are not diabetics eat it all the time ... Y Yes, because they [older people] have had more experience about learning how to cope with things and stuff, and we're just young people. We never learned how to cope with all this stuff yet. So, it's harder for us to stay away from it than just to, just eat it (Adolescent 2).

Halloween's the hardest time ... . Especially when you have a bag of candy in your closet just begging to be eaten (Adolescent 4).

Yes, because temptations, there's a lot of temptation there (Adolescent 1). 
So sometimes, if you want, like what I say is if I want just a bit of that, I should only make myself take this because it might not have that much sugar. I should know as - the other stuff, I should know how much sugar there is in it comparing to that or whatever (Adolescent 6).

[Discussing what would happen if they ate like their friends] ... my blood glucose would be through the roof and l'd be sick and sweating, you know, kind of stuff and going, oh, my gosh, and taking blood glucoses and giving myself insulin to kind of get it to go down, go for a walk or something, try to get it down. You'd be like peeing every 2 seconds because of all of that, because the body's trying to get all the sugars and stuff out. It's not working (Adolescent 1).

Adolescents communicated a good understanding of the types of foods that helped with diabetes management, and those that did not. They also showed an understanding of broad factors that affected their ability to eat as recommended by diabetes clinicians and educators, such as lack of access to healthy food and budgetary constraints. Many adolescents prioritized their family's needs over their own.

Green, actual food (Adolescent 2).

And sometimes it's really hard because things they ask you to do, like what type of foods, it costs a lot of money (Adolescent 4).

Like even carbs, you can get your hands on them, but vegetables and fruits and all that stuff, it's like... (Adolescent 4).

And on that too, I saw on the news that produce is going up in the supermarket. So, if you want to go buy like a bunch of grapes and some stuff, it will cost you more to buy that than it would cost you to buy junk food. So, if you have the money, you're like, okay, well, I can't afford that. I can afford this, the junk. So, you'd buy the junk. So that's what I think (Adolescent 1).

Because like you'll spend like $\$ 20$ easy on just a bag of grapes and maybe not much apples, but for $\$ 20$ at a fast food restaurant you can get a full course meal that isn't healthy for you (Adolescent 2).

Every food I need is too expensive and cheaper foods are much easier, especially in my family, because bills keep going higher, so we have to get cheap foods (Adolescent 3).

So, with healthy stuff, it's like the small pile and ... I need to feed other people with the money I'm getting, so ... (Adolescent 3).

\section{Supports}

Adolescents talked about the impact of support, and lack of support, on their experience of living with diabetes. Adolescents received support from family, friends and their school environment.

[My parent says] don't eat all of it at one time ... they check in on me (Adolescent 1).

Yes, last night my [family member] got mad at me because I got too carried away with chips (Adolescent 3 ).
My [parent] can't do that for me because they're too busy to check up on me (Adolescent 4).

Like my [family member] banned energy drinks to me and [other children] ... but my [family member] buys their own things and it's kind of tempting when they buy energy drinks. They only let me drink like a tiny bit and then they take it away (Unknown speaker).

Yes, my [family member] is a little bit nagging. I know they don't want me to get hurt or nothing, but say, as I was saying earlier, they reversed their diabetes and they're like a really fit person [family member no longer requires medications for diabetes] (Adolescent 1 ).

It's just, you know, sometimes my friends and I forget that ... well, they don't know much about diabetes, so sometimes they'll give me like a higher sugar drink or ... (Adolescent 6).

\section{Independence and goals}

Despite the challenges of living with diabetes, adolescents expressed pride in making decisions that they thought would benefit their health and they identified goals for their future.

[Independence is] like self-control (Adolescent 1).

[Independence is] It's like you want to think about your health ... instead of thinking about all that delicious crap (Adolescent 6).

We're thinking about the future (Adolescent 2).

[My goal] is to bring my sugars to a normal level, like stay there and.... And then a healthy lifestyle ... healthy food and exercise (Adolescent 7).

Losing weight's a big part of it [i.e., goal] (Adolescent 2).

I would say stay fit (Adolescent 4).

Well, getting off of insulin (Adolescent 7).

Prevent kids from. ... Getting diabetes (Adolescent 7).

Yes ... I don't want my kids to go through all the crap that I went through (Adolescent 1).

Valuable knowledge and insights from the discussions with adolescents have been translated into public health and social media messaging, including a knowledge translation infographic for First Nation communities (Figure 1).

\section{Interpretation}

We identified and prioritized aspects of the lived experience of adolescents with type 2 diabetes to inform future research and clinical care and ensure its relevance for adolescent patients. This study shares the perspectives of adolescents with type 2 

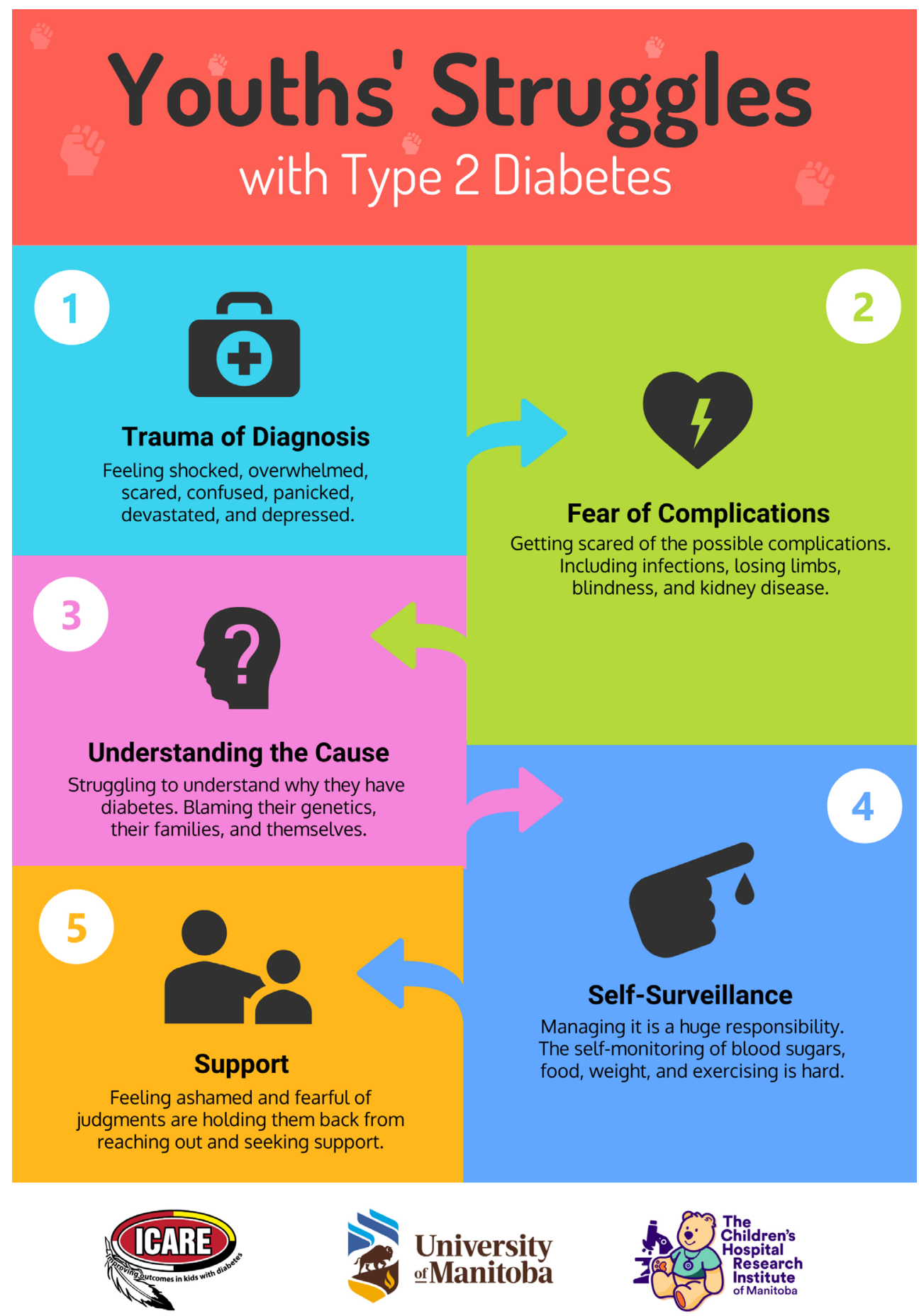

Figure 1: Infographic developed and designed by adolescents living with type 2 diabetes mellitus to share the barriers to living well with type 2 diabetes, from their lived experience.

diabetes, which has been missing from literature on the lived experiences of patients with type 2 diabetes. Our results reflect those of other studies reporting high rates of stress and diabetes distress in pediatric patients with type 1 diabetes, ${ }^{15,16}$ and adult patient perspectives on living with type 2 diabetes, which emphasized the importance of family and provider support and the need for increased awareness and understanding of the impact of diabetes in the context of the patient's life. ${ }^{8}$ Shared experiences between these populations and the adolescents with type 2 diabetes in our study include the stressful demands of chronic disease management and the desire for increased understanding from peers, family members and health care providers. However, the level of distress at the time of diagnosis is unique to our cohort of youth with type 2 diabetes, signifying the depth of knowledge adolescents had about diabetes before diagnosis. Many people have little pre-existing knowledge about any new 
diagnosis and learn about their disease at diagnosis. Although adolescents living with diabetes in our study still had much to learn, they already had a profound understanding of diabetes that shaped their motivations, their thoughts about their futures and their self-care practices. The endemic nature of diabetes within some First Nations communities shaped the experience and perceptions of the condition for these adolescents.

The impact of environment and culture on the lived experience has been reported among adults living with type 2 diabetes in sub-Saharan Africa. ${ }^{17}$ Notably, patients described their experience with type 2 diabetes as a sociocultural disease, affected by their physical, social and emotional environment. In addition to these concepts, our adolescents voiced knowledge and fear of diabetes-related complications which, to date, has only been reported in adult literature and speaks to the intergenerational trauma that diabetes imparts onto families.

\section{Limitations}

Limitations of our study include the selection of a convenience sample of adolescents from a diabetes clinic, which may result in missing specific themes or priorities of other youth with type 2 diabetes who did not participate. Lack of proximity and availability prevented some adolescents from participating. The extensive costs (both in time and money) and the lack of funding to bolster participation from adolescents residing in remote Northern communities likely means that some of the issues, specific to those communities that are most affected by pediatric type 2 diabetes, were not identified or discussed.

\section{Conclusion}

Traditional concepts of type 2 diabetes as a lifestyle-driven, preventable disease results in substantial stigma and shame associated with the diagnosis for adolescents, which may be a barrier to self-care. A broadening of the definition and pathophysiological understanding of adolescent-onset type 2 diabetes to include socioecological and emotional context can help to improve health care provision and communication with patients and their families.

\section{References}

1. Divers J, Mayer-Davis EJ, Lawrence JM, et al. Trends in incidence of type 1 and type 2 diabetes among youths: selected counties and Indian reservations, United States, 2002-2015. MMWR Morb Mortal Wkly Rep 2020;69:161-5.

2. Sellers EAC, Wicklow BA, Dean HJ. Clinical and demographic characteristics of type 2 diabetes in youth at diagnosis in Manitoba and Northwestern Ontario (2006-2011). Can J Diabetes 2012;36:114-8.

3. Amed S, Dean HJ, Panagiotopoulos C, et al. Type 2 diabetes, medicationinduced diabetes, and monogenic diabetes in Canadian children: a prospective national surveillance study. Diabetes Care 2010;33:786-91.

4. RISE Consortium; RISE Consortium Investigators. Effects of treatment of impaired glucose tolerance or recently diagnosed type 2 diabetes with metformin alone or in combination with insulin glargine on $\beta$-cell function: comparison of responses in youth and adults. Diabetes 2019;68:1670-80.

5. Kelsey MM, Geffner ME, Guandalini C, et al. Treatment options for Type 2 diabetes in Adolescents and Youth Study Group. Presentation and effectiveness of early treatment of type 2 diabetes in youth: lessons from the TODAY study. Pediatr Diabetes 2016;17:212-21.

6. Domecq JP, Prutsky G, Elraiyah T, et al. Patient engagement in research: a systematic review. BMC Health Serv Res 2014;14:89.

7. Murad MH, Shah ND, Van Houten HK, et al. Individuals with diabetes preferred that future trials use patient-important outcomes and provide pragmatic inferences. J Clin Epidemiol 2011;64:743-8.

8. Ndjaboue R, Chipenda Dansokho S, Boudreault B, et al. Patients' perspectives on how to improve diabetes care and self-management: qualitative study. BMJ Open 2020;10:e032762.

9. Kovach M. Indigenous methodologies: characteristics, conversations, and contexts. Toronto: University of Toronto Press; 2009.

10. Tuhiwai Smith L. Decolonizing methodologies: research and Indigenous peoples. 2nd ed. London (UK): Zed Books; 2012.

11. Canadian Institutes of Health Research; Natural Sciences and Engineering Research Council of Canada; Social Sciences and Humanities Research Council. Tri-Council Policy Statement (TCPS-2): ethical conduct of research involving humans - TCPS2 2018.

12. Tong A, Sainsbury P, Craig J. Consolidated criteria for reporting qualitative research (COREQ):a 32-item checklist for interviews and focus groups. Int J Qual Health Care 2007;19:349-57.

13. Thorne S, Kirkham SR, O'Flynn-Magee K. The analytic challenge in interpretive description. Int J Qual Methods 2004;3:1-11.

14. Agarwal P, Brar N, Morriseau TS, et al. Gestational diabetes adversely affects pancreatic islet architecture and function in the male rat offspring. Endocrinology 2019;160:1907-25.

15. Kent DA, Quinn L. Factors that affect quality of life in young adults with type 1 diabetes. Diabetes Educ 2018;44:501-9.

16. Majidi S, Driscoll KA, Raymond JK. Anxiety in children and adolescents with type 1 diabetes. Curr Diab Rep 2015;15:47.

17. Masupe TK, Ndayi K, Tsolekile L, et al. Redefining diabetes and the concept of self-management from a patient's perspective: implications for disease risk factor management. Health Educ Res 2018;33:40-54.

\section{Competing interests: None declared.}

This article has been peer reviewed.

Affiliations: Department of Pediatrics and Child Health (Wicklow, Dart), University of Manitoba; Children's Hospital Research Institute of Manitoba (Wicklow, Dart), Winnipeg, Man.; Waywayseecappo First Nation (McKee), Waywayseecappo, Man.; Brandon University (Griffiths), Brandon, Man.; Department of Clinical Health Psychology (Malik), University of Manitoba, Winnipeg, Man.; Wabaseemoong First Nation (Quoquat), Whitedog, Ont.; Department of Community Health Sciences (Bruce), University of Manitoba, Winnipeg, Man.

Contributors: Brandy Wicklow, Allison Dart, Sayma Malik and Sharon Bruce designed and participated in the focus group and wrote and edited the manuscript. Sharon Bruce provided qualitative research expertise and led data analysis. All authors participated in the interpretation of the data, revised it critically for important intellectual content, gave final approval of the version to be published and agreed to be accountable for all aspects of the work.

Content licence: This is an Open Access article distributed in accordance with the terms of the Creative Commons Attribution (CC BY-NC-ND 4.0) licence, which permits use, distribution and reproduction in any medium, provided that the original publication is properly cited, the use is noncommercial (i.e., research or educational use), and no modifications or adaptations are made. See: https://creativecommons. org/licenses/by-nc-nd/4.0/
Funding: This project was funded by Diabetes Canada, Research Manitoba and the Canadian Institutes of Health Research (MOP 142309).

Data sharing: As per the First Nations Principles of OCAP (ownership, control, access and possession), and the context of this study, which requires participant engagement in interpretation of focus group transcripts, the authors do not feel it would be appropriate to share data. Interested parties can contact the corresponding author with further inquiries.

Accepted: Jan. 4, 2021

Correspondence to: Brandy Wicklow, bwicklow@hsc.mb.ca 